\title{
EDITORIAL
}

\section{SETLA: una casa abierta}

\section{SETLA: an open house}

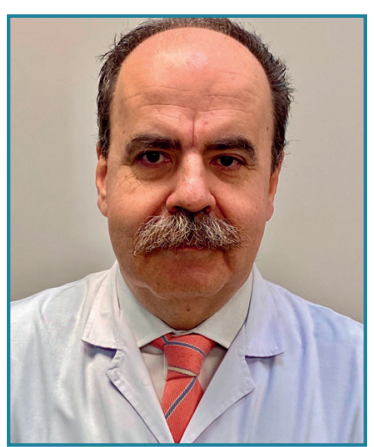

José R. García López Vicepresidente de SETLA

\section{Queridos amigos:}

Me siento honrado por tener la oportunidad de dirigirme a vosotros en este foro tan importante para nuestra sociedad como es la Revista Española de Traumatología Laboral (RETLA). Desde hace unos años, viene dándonos alegrías semestrales con números que conjugan una elaboración cuidadosa y unos contenidos del máximo nivel académico. Cualquier publicación científica no debe tener otro objetivo que poner en común experiencias profesionales con la comunidad médica. Así se creó nuestra revista, para ofrecer a los lectores información actualizada sobre el campo de la medicina y la traumatología laboral.

Es obligado rendir tributo y reconocimiento histórico a su creador, el Dr. García Lomas, cuyo impulso docente hizo que la revista comenzará su recorrido. Así como al Dr. Á. García Berlinches, pues fue durante su presidencia cuando la revista de la sociedad adquirió su formato actual.

Es un orgullo para la SETLA contar con sus dos editores, los doctores J. Aguilera Repiso y E. Sánchez Alepuz. Sin la combinación de su esfuerzo, tesón y conocimientos no hubiese sido posible haceros llegar los contenidos científicos de nuestros autores. A ellos les debemos el gran nivel de prestigio alcanzado.

La SETLA ha demostrado su capacidad de adaptarse a situaciones tan complejas como el terrible momento sociosanitario que estamos viviendo. Este nuevo escenario, en el que la presencialidad se ha visto reemplazada por la formación on-line, nos ha metido de lleno en un nuevo método, inédito para nosotros, de transmitir conocimiento. Y, con orgullo, podemos afirmar que hemos salvado las dificultades que entrañaba la situación de una manera sobresaliente. Es encomiable, en ese sentido, el éxito obtenido por las webinars organizadas, por primera vez, estos dos últimos años. Vaya, desde aquí, mi felicitación y reconocimiento al esfuerzo realizado por los organizadores y participantes de las mismas.

El séptimo número de nuestra revista ahora ve la luz. Como podréis comprobar, en ella se abordan una diversidad de temas que no hacen otra cosa que retratar nuestra identidad. Pocas sociedades pueden presumir de cohesionar de forma transversal a todos los colectivos que nos dedicamos a esta rama de la

$\mathbf{F S}$ https://doi.org/10.24129/j.retla.04107.fs2105011

๑ 2021 Sociedad Española de Traumatología Laboral. Publicado por Imaidea Interactiva en FONDOSCIENCE ${ }^{\circledR}$ (www.fondoscience.com). Este es un artículo Open Access bajo la licencia CC BY-NC-ND (www.creativecommons.org/licenses/by-nc-nd/4.0/). 
salud. Traumatología, medicina asistencial, enfermería, fisioterapia... se unen para dar forma y contenido, una vez más, a nuestra publicación.

La revista es, como toda nuestra sociedad, una casa abierta a todos vosotros, por lo que os animo a colaborar en ella. Estamos en disposición de prestaros toda la ayuda necesaria para dar forma a vuestros trabajos. No dudéis en contactar con nosotros.

Sirva como despedida recordaros que sigue vivo el compromiso de esta Junta Directiva, con su presidente a la cabeza, con el objetivo principal de la sociedad, que no es otro que el fomento de la enseñanza, el estudio, la investigación y la práctica de todos los aspectos relacionados con la traumatología laboral. Nuestra revista es, sin duda, fiel exponente de ello.

Con la esperanza de que este número cumpla vuestras expectativas, os envío un caluroso abrazo.

Dr. José R. García López

Vicepresidente de SETLA 